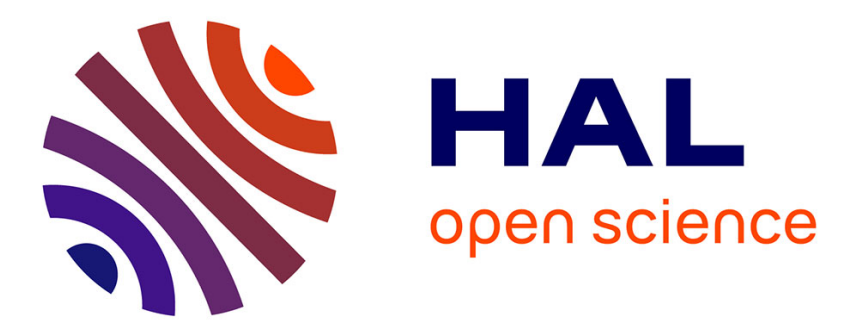

\title{
Anomalous electric transport across Verwey transition in nanocrystalline Fe3O4 thin films
}

Murtaza Bohra, Dibakar Roy Chowdhury, Jean-François Bobo, Vidyadhar Singh

\section{- To cite this version:}

Murtaza Bohra, Dibakar Roy Chowdhury, Jean-François Bobo, Vidyadhar Singh. Anomalous electric transport across Verwey transition in nanocrystalline Fe3O4 thin films. Journal of Applied Physics, 2019, 10.1063/1.5058150 . hal-02363596

\section{HAL Id: hal-02363596 https://hal.science/hal-02363596}

Submitted on 14 Nov 2019

HAL is a multi-disciplinary open access archive for the deposit and dissemination of scientific research documents, whether they are published or not. The documents may come from teaching and research institutions in France or abroad, or from public or private research centers.
L'archive ouverte pluridisciplinaire HAL, est destinée au dépôt et à la diffusion de documents scientifiques de niveau recherche, publiés ou non, émanant des établissements d'enseignement et de recherche français ou étrangers, des laboratoires publics ou privés. 
See discussions, stats, and author profiles for this publication at: https://www.researchgate.net/publication/329873720

\section{Anomalous electric transport across Verwey transition in nanocrystalline $\mathrm{Fe} 3 \mathrm{O} 4$ thin films}

Preprint in Journal of Applied Physics · December 2018

DOI: $10.1063 / 1.5058150$

CITATIONS

2

3 authors:

Murtaza Bohra

Mahindra Ecloe Centrale, Hyderabd

51 PUBLICATIONS 400 CITATIONS

SEE PROFILE

C.. Jean-Francois Bobo

French National Centre for Scientific Research

159 PUBLICATIONS 2,300 CITATIONS

SEE PROFILE

Some of the authors of this publication are also working on these related projects:

Synthesis, Properties, and Applications of Multifunctional Magnetic Nanostructures 2018 View project

Gas-phase synthesis of bimetallic/trimetallic nanoparticles View project
143

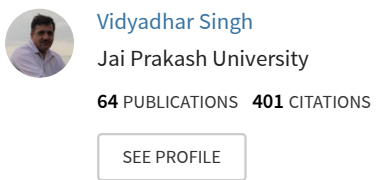


Anomalous electric transport across Verwey transition in nanocrystalline $\mathrm{Fe}_{3} \mathrm{O}_{4}$ thin films

Murtaza Bohra, Dibakar Roy Chowdhury, Jean-François Bobo, and Vidyadhar Singh

Citation: Journal of Applied Physics 125, 013901 (2019); doi: 10.1063/1.5058150

View online: https://doi.org/10.1063/1.5058150

View Table of Contents: http://aip.scitation.org/toc/jap/125/1

Published by the American Institute of Physics

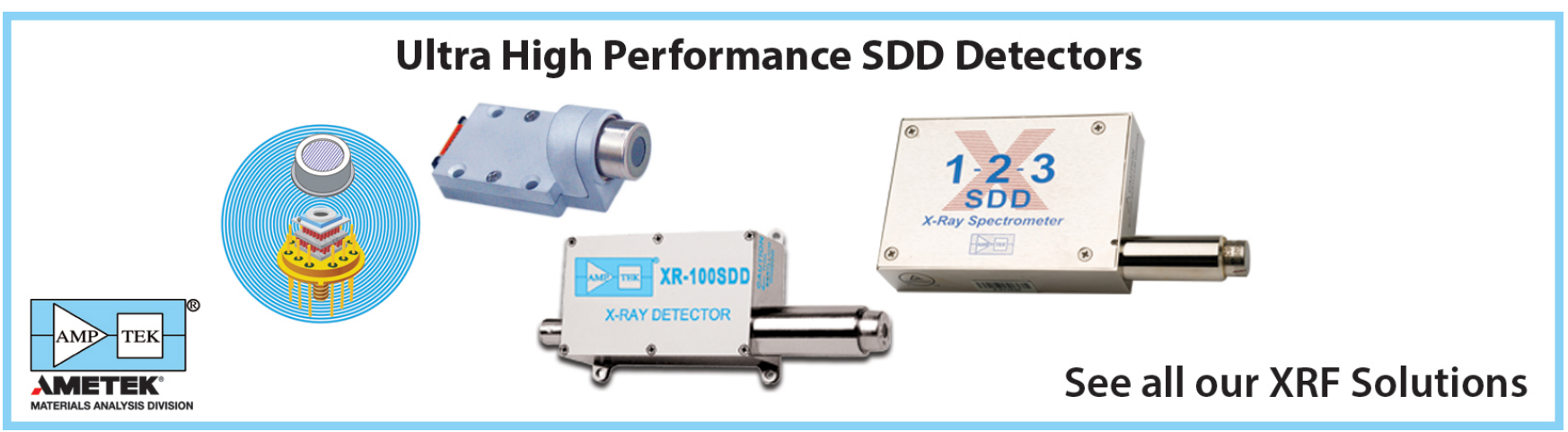




\title{
Anomalous electric transport across Verwey transition in nanocrystalline $\mathrm{Fe}_{3} \mathrm{O}_{4}$ thin films
}

Cite as: J. Appl. Phys. 125, 013901 (2019); doi: 10.1063/1.5058150

Submitted: 17 September 2018 . Accepted: 13 December 2018 .

Published Online: 2 January 2019

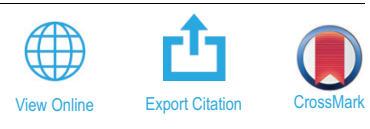

Murtaza Bohra, ${ }^{1, a)}$ (i) Dibakar Roy Chowdhury, ${ }^{1}$ (D) Jean-François Bobo, ${ }^{2}$ (D) and Vidyadhar Singh ${ }^{3,4}$ (iD)

\begin{abstract}
AFFILIATIONS
${ }^{7}$ Mahindra Ecole Centrale College of Engineering, Survey no: 62/1A, Bahadurpally Jeedimetla, Hyderabad 500043, Telangana, India

${ }^{2}$ Centre d'Elaboration de Materiaux et d'Etudes Structurales (CEMES), 29 rue Jeanne Marvig, 31055 Toulouse Cedex 4, France

${ }^{3}$ Department of Physics, Jai Prakash University, Chapra 841301, Bihar, India

${ }^{4}$ Nanoparticles by Design Unit, Okinawa Institute of Science and Technology Graduate University, 1919-1 Tancha Onna-Son, Okinawa 904-0495, Japan
\end{abstract}

a) Author to whom correspondence should be addressed: murtazaphy@gmail.com

\begin{abstract}
Charge ordering $\left(\mathrm{Fe}^{+3} / \mathrm{Fe}^{+2}\right)$ is a key concept in the Verwey transition of $\mathrm{Fe}_{3} \mathrm{O}_{4}$ because it frequently competes with functional properties (half-metallicity/ferromagnetism and structural transformation) and quantum confinement effect, especially at nanoscale dimensions. In this paper, we report the fabrication of nanocrystalline $\mathrm{Fe}_{3} \mathrm{O}_{4}$ thin films via two different reduction routes, namely, vacuum annealing and wet $\mathrm{H}_{2}$ annealing. While vacuum annealed films exhibit Verwey transition and resistivity values comparable to bulk $\mathrm{Fe}_{3} \mathrm{O}_{4}$, the same is not observed in electric transport properties of wet $\mathrm{H}_{2}$ annealed films. However, this transition was visible in the magnetic characteristics exhibited by both the films though realized via different routes. This observation indicates the possibility of charge and spin ordering as two independent phenomena, and it is a coincidence that happens at the same Verwey transition region. It is seen that a crossover from thermally activated hopping (300-120 K) to Mott variable range hopping (VRH) (across Verwey transition) and then to Shklovskii-Efros VRH hopping (70-30 K) via the conduction mechanism takes place in vacuum annealed films in contrast to the typical semiconducting behavior (300-50 K) expected of wet $\mathrm{H}_{2}$ annealed films. Different electric transport properties in both varieties of $\mathrm{Fe}_{3} \mathrm{O}_{4}$ films could be ascribed to the electronic disorder/defects affecting charge ordering $\mathrm{Fe}^{+3} / \mathrm{Fe}^{+2}$ and trimerons $\left(\mathrm{Fe}^{+3}-\mathrm{Fe}^{+2}-\mathrm{Fe}^{+3}\right)$.
\end{abstract}

Published under license by AIP Publishing. https://doi.org/10.1063/1.5058150

\section{INTRODUCTION}

Verwey transition, particularly, in nano-sized strongly correlated magnetite $\left[\mathrm{Fe}_{3} \mathrm{O}_{4}:\left(\mathrm{Fe}^{+3}\right)_{\mathrm{A}}\left(\mathrm{Fe}^{+2}, \mathrm{Fe}^{+3}\right)_{\mathrm{B}} \mathrm{O}_{4}\right]$ materials, continues to draw the attention of researchers involved with spintronics and the physics associated with it. ${ }^{1-3}$ Electron hopping between $\mathrm{Fe}^{+2}$ and $\mathrm{Fe}^{+3}$ ions at octahedral $\mathrm{B}$-sites facilitates room temperature electric conductivity $\sigma=200(\Omega \mathrm{cm})^{-1}$ in $\mathrm{Fe}_{3} \mathrm{O}_{4}$. Otherwise, most of the ferrites derived from it are insulators. Besides, $\mathrm{Fe}_{3} \mathrm{O}_{4}$ owns only minority $t_{2 g}$ spin band at the Fermi level, thereby demonstrating half-metallic character, which has triggered many applications. ${ }^{4,5}$ The transformation of this curious metallic state of $\mathrm{Fe}_{3} \mathrm{O}_{4}$ to an insulating state below $120 \mathrm{~K}\left(\mathrm{~T}_{\mathrm{V}}\right)$ is essentially known as the Verwey transition. ${ }^{6}$ Consequently, the crystal structure of $\mathrm{Fe}_{3} \mathrm{O}_{4}$ also transforms from a cubic to a monoclinic structure due to the Jahn-Teller distortion of $\mathrm{Fe}^{+2}$ ions. The monoclinic structure is connected to the complex electronic order of $\mathrm{Fe}^{+2} / \mathrm{Fe}^{+3}$ charges, $\mathrm{Fe}^{+2}$ orbital states, and metal-metal weakly bonded $\mathrm{Fe}_{3}$ units known as trimerons, ${ }^{4,7-9}$ which means that electrons are not fully localized as $\mathrm{Fe}^{+2}$ states, but, instead, are spread over the three sites $\mathrm{Fe}^{+3}-\mathrm{Fe}^{+2}-\mathrm{Fe}^{+3}$. However, there still exist uncertainties as to the precise mechanism responsible for this electrical and structural transition. Further, the consequential influence of magnetic properties on the transition and its electronic characteristic is still unclear, ${ }^{7-10}$ particularly for nanocrystalline $\mathrm{Fe}_{3} \mathrm{O}_{4}$ films.

The Verwey transition has found a lot of advanced technological applications, for example, in an enhancement of resistive switching, spin accumulation, spin Seebeck and 
magneto-caloric effects, switchover from giant magnetoresistance (MR) to tunnel magnetoresistance in a single spin valve ${ }^{11-16}$ etc. It is, therefore, important to investigate the Verwey transition in nanocrystalline $\mathrm{Fe}_{3} \mathrm{O}_{4}$ films to get a better insight into the mechanism of spin-lattice-charge coupling. Most of these $\mathrm{Fe}_{3} \mathrm{O}_{4}$ films are post-annealed for the improvement of the electrical performance and stability of the spintronic devices. Typically in pulsed laser deposition and sputtering processes, ${ }^{17,18}$ it is observed that $\mathrm{Fe}_{3} \mathrm{O}_{4}$ films grown at low temperatures are formed out of amorphous and mixed oxide phases and antiphase boundaries. ${ }^{17-22}$ Therefore, it is very important to optimize the different reduction processes to get bulk stoichiometric $\mathrm{Fe}_{3} \mathrm{O}_{4}$ properties.

In this study, we investigate the electric transport properties across the Verwey transition of nanocrystalline $\mathrm{Fe}_{3} \mathrm{O}_{4}$ films produced by two different reduction methods. Our findings suggest that electric transport is an independent process and it hardly has any correlation with the magnetization process and it depends on external and internal factors that arise from the involved complexities in the reduction methods.

\section{EXPERIMENTAL}

Thin films were first laser-ablated from an $\alpha-\mathrm{Fe}_{2} \mathrm{O}_{3}$ ceramic target on to fused quartz substrates at three different growth temperatures $\left(\mathrm{T}_{\mathrm{g}}\right)$ : RT, 350 , and $500^{\circ} \mathrm{C}$ in a vacuum of $1 \times 10^{-5}$ mbar. ${ }^{17,23}$ These films undergo two different reduction processes, namely, vacuum annealing and wet $\mathrm{H}_{2}$ annealing. ${ }^{17}$ For vacuum annealing, after the deposition, the samples were in situ annealed at $500^{\circ} \mathrm{C}$ for $1 \mathrm{~h}$ in vacuum $\sim 4 \times 10^{-6}$ mbar. For wet $\mathrm{H}_{2}$ annealing, as-grown films were ex situ annealed in a tubular furnace at $450{ }^{\circ} \mathrm{C}$ in wet $\mathrm{H}_{2}$ gas atmosphere for 15 min. X-ray diffraction (XRD) of the films was taken by a PANalytical X'Pert PRO X-ray diffractometer using $\mathrm{CuK}_{\alpha}$ radiation. X-ray photoelectron spectra (XPS) were collected on a Microtech Unit ESCA 3000 Spectrometer with source MgKa $(1256.6 \mathrm{eV})$. The transmission electron microscopy (TEM) micrographs were collected from a Philips CM 200 transmission electron microscope. Electrical transport measurements were performed using a four-probe method in between 30 and $300 \mathrm{~K}$. The micro-Raman spectra were recorded in the range of $100-1000 \mathrm{~cm}^{-1}$ with a $6 \mathrm{~mW}, 514.5 \mathrm{~nm} \mathrm{Ar}^{+}$laser source. Magnetization (M) vs temperature (T) curves were measured at various magnetic fields using a Quantum design PPMS.

\section{RESULTS}

Figure 1(a) represents the XRD patterns of vacuum and wet $\mathrm{H}_{2}$ annealed films of different $\mathrm{T}_{\mathrm{g}}$ values. Vacuum annealed films show sharp peaks corresponding to $\mathrm{Fe}_{3} \mathrm{O}_{4}$ phase at all $\mathrm{T}_{\mathrm{g}}$ values. Wet $\mathrm{H}_{2}$ annealed films show comparatively broad $\mathrm{Fe}_{3} \mathrm{O}_{4}$ peaks along with the amorphous background of quartz substrates. This indicates a relatively better crystallinity in the vacuum deposited films. The average grain sizes estimated from the Scherrer formula using high-intensity $\mathrm{Fe}_{3} \mathrm{O}_{4}$ peak width were found to be in the range $50-83 \mathrm{~nm}$ (vacuum annealed) and 22-60 nm (wet $\mathrm{H}_{2}$ annealed), respectively. Larger grain sizes in the former sets of films are further

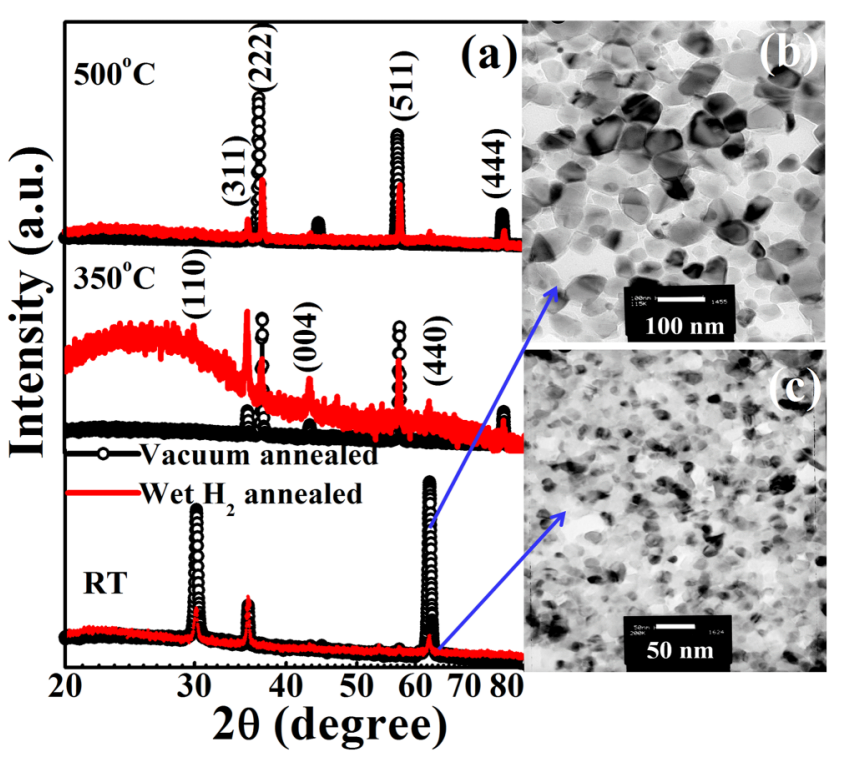

FIG. 1. (a) XRD patterns of vacuum and wet $\mathrm{H}_{2}$ annealed films of different $T_{\mathrm{g}}$ values; ${ }^{16}[(\mathrm{~b})$ and $(\mathrm{c})]$ TEM micrographs for both varieties of films for one of the representatives $T_{\mathrm{g}}=\mathrm{RT}$.

confirmed from TEM images for one of the representative samples with $\mathrm{T}_{\mathrm{g}}=\mathrm{RT}$ [Figs. 1(b) and 1(c)]. No other oxides $\left(\alpha-\mathrm{Fe}_{2} \mathrm{O}_{3}, \mathrm{FeO}\right.$, and $\left.\gamma-\mathrm{Fe}_{2} \mathrm{O}_{3}\right)$ and elemental Fe impurity phases could be seen in either case within the accuracy limit set by the XRD and the XPS equipment (shown in Fig. S1 in the supplementary material), which is also supported by Raman studies (shown later). Irrespective of reduction methods, all films exhibit lattice constants $(a=8.37-8.39 \AA)$ close to the known value for cubic bulk $\mathrm{Fe}_{3} \mathrm{O}_{4}(8.39 \AA)$ structure.

To understand the effect of microstructural difference on electric transport behavior, the resistivity $(\rho)$ vs temperature (T) curves for wet $\mathrm{H}_{2}$ and vacuum annealed films grown at different $\mathrm{T}_{\mathrm{g}}$ values are plotted in Figs. 2(a) and 2(b), respectively. The room temperature $\rho$ values (as shown in Table I) of $4.4-40 \mathrm{~m} \Omega \mathrm{cm}$ for vacuum annealed films are close to the known single crystal $\mathrm{Fe}_{3} \mathrm{O}_{4}$ value of $4 \mathrm{~m} \Omega \mathrm{cm}^{24}$ but smaller than wet $\mathrm{H}_{2}$ annealed films $(90-250 \mathrm{~m} \Omega \mathrm{cm})$. The $\rho$-T curves are also quite different in both sets of films. The resistivity of wet $\mathrm{H}_{2}$ annealed films gradually increases upon lowering the temperatures $(300-50 \mathrm{~K})$, but in the case of vacuum annealing, the $\rho$-T curve initially varies very slowly, and after passing through a kink, it starts increasing rapidly. Such a kink $(115-125 \mathrm{~K})$ in the $\rho-\mathrm{T}$ curve is a clear signature of the Verwey transition. However, this transition is not as sharp as was reported in the case of single crystal $\mathrm{Fe}_{3} \mathrm{O}_{4}$ at $120 \mathrm{~K}^{25}$

Interestingly, M-T curves [insets of Figs. 1(a) and 1(b)] show clear Verwey transition around $120 \mathrm{~K}$ irrespective of the methods used for reduction. Except for the Verwey transition, 


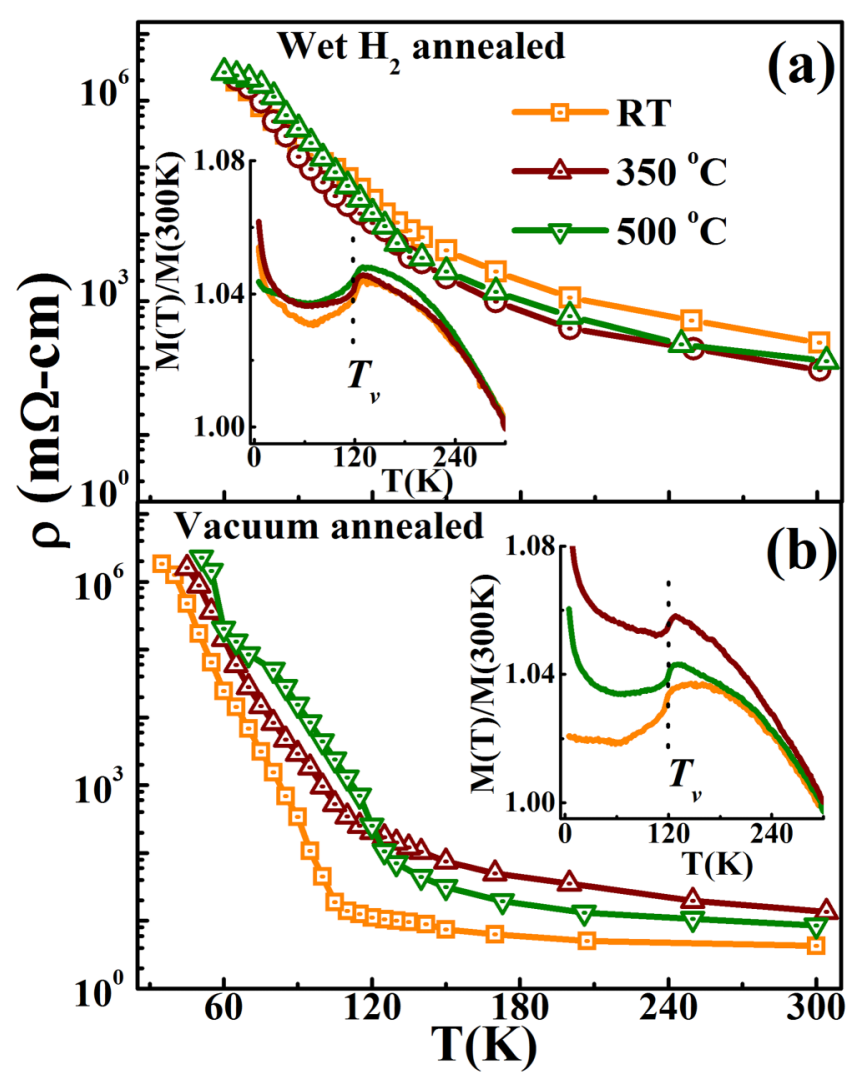

FIG. 2. (a) $\rho-T$ curves of wet $\mathrm{H}_{2}$ and vacuum annealed (b) films at different $T_{\mathrm{g}}$ values. Corresponding $M-T$ curves (measured at $2 \mathrm{~T}$ ) are also given in their respective insets.

M-T curves do not show any other peaks, which exclude the possibility of spin blocking process because our grain sizes exceed the superparamagnetic size limit of $\mathrm{Fe}_{3} \mathrm{O}_{4}$ and show typical ferrimagnetic behavior. ${ }^{13,17}$ Another apparent difference is that the $\rho-\mathrm{T}$ and $\mathrm{M}-\mathrm{T}$ curves of vacuum annealed films are significantly influenced by in situ growth temperature $\mathrm{T}_{g}$.

TABLE I. Room temperature resistivity $(\rho)$ and magnetoresistance (MR) values, activation energy $\left(E_{\mathrm{g}}\right), T_{\mathrm{M}}$, and $T_{\mathrm{SE}}$ for vacuum and wet $\mathrm{H}_{2}$ annealed $\mathrm{Fe}_{3} \mathrm{O}_{4}$ films at different $T_{\mathrm{g}}$ values.

\begin{tabular}{|c|c|c|c|c|c|c|c|c|}
\hline \multirow[b]{2}{*}{$\begin{array}{l}T_{\mathrm{g}} \\
\left({ }^{\circ} \mathrm{C}\right)\end{array}$} & \multicolumn{5}{|c|}{ Vacuum annealed films } & \multicolumn{3}{|c|}{ Wet $\mathrm{H}_{2}$ annealed films } \\
\hline & $\begin{array}{l}\rho(300 \mathrm{~K}) \\
(\mathrm{m} \Omega \mathrm{cm})\end{array}$ & $\begin{array}{c}E_{\mathrm{g}} \\
(\mathrm{meV})\end{array}$ & $\begin{array}{c}T_{\mathrm{M}} \\
\left(10^{8} \mathrm{~K}\right) \\
\end{array}$ & $\begin{array}{l}T_{\mathrm{SE}} \\
(\mathrm{K}) \\
\end{array}$ & $\begin{array}{c}M R \\
(300 \mathrm{~K}) \\
(\%) \\
\end{array}$ & $\begin{array}{c}\rho \\
(300 \mathrm{~K}) \\
(\mathrm{m} \Omega \mathrm{cm})\end{array}$ & $\begin{array}{c}E_{g} \\
(\mathrm{meV})\end{array}$ & $\begin{array}{c}\text { MR } \\
(300 \\
\text { K) (\%) } \\
\end{array}$ \\
\hline TT & 4.4 & 20 & 9. & 2310 & -0 & 240 & 81 & -1.81 \\
\hline 50 & 14 & 78 & & & $-c$ & 93 & 86 & -2.05 \\
\hline 500 & 8.4 & 44 & 4.7 & 21025 & -0.9 & 126 & 84 & -2.25 \\
\hline
\end{tabular}

\section{DISCUSSIONS}

It is clear from the above results that the in situ growth temperature influences physical properties of vacuum annealed films to some extent, but the same is not evident in the cases of wet $\mathrm{H}_{2}$ annealed films. This can be understood from the fact that vacuum annealing was carried out just after deposition while keeping the vacuum level almost intact and raising annealing temperature. This results in robust crystalline growth and reduction of any residual $\mathrm{Fe}_{2} \mathrm{O}_{3}$ phase into $\mathrm{Fe}_{3} \mathrm{O}_{4}$. We feel that during initial deposition, crystallites not detectable by XRD were formed, which act as nucleation centers for further crystallization during post-deposition annealing. ${ }^{26}$ Thus, the initial deposition conditions leave their signature on the as-deposited films, which determine the texture and physical properties of the films when annealed. However, the wet $\mathrm{H}_{2}$ annealing process $^{17}$ involves two steps: all the samples irrespective of their in situ growth temperatures were first ex situ annealed in air to convert them into complete $\mathrm{Fe}_{2} \mathrm{O}_{3}$ phase. In the second step, wet $\mathrm{H}_{2}$ gas was passed over the samples to obtain the end product $\mathrm{Fe}_{3} \mathrm{O}_{4}$. In the wet $\mathrm{H}_{2}$ reduction process, complete grain refinement takes place, which results in smaller grain sizes of $\mathrm{Fe}_{3} \mathrm{O}_{4}$ with presumably distorted surfaces compared to vacuum annealed films. Thereby, all wet $\mathrm{H}_{2}$ annealed films show almost identical behavior and the initial in situ growth temperature has hardly any effect.

A notable feature observed in the present study is that the vacuum annealed films show the Verwey transition in $\rho-\mathrm{T}$ curves, while the same is not seen in wet $\mathrm{H}_{2}$ annealed films. It is quite surprising that magnetization shows the Verwey transition in both sets of films, but their electronic transport properties behave differently. Systematic studies ${ }^{2,3}$ on stoichiometric $\mathrm{Fe}_{3} \mathrm{O}_{4}$ nanocrystals $(5-100 \mathrm{~nm})$, however, show the occurrence of concurrent Verwey transition in conductance, magnetization, nuclear magnetic resonance, cryo-XRD, and heat capacity measurements. The Verwey transition was weakly size-dependent below $40 \mathrm{~nm}$ and became suppressed in nanocrystals smaller than $20 \mathrm{~nm}$ before disappearing completely for less than $6 \mathrm{~nm}$; even in that sense also, our samples overcome the grain size threshold. Kim et al., ${ }^{27}$ in their recent work, reported that the Verwey transition exhibits large size-dependent thermal hysteresis in the magnetization data and that the hysteresis width is correlated with the critical size of the single magnetic domain. They also anticipated stronger coupling between charge and spin degrees of freedom in $\mathrm{Fe}_{3} \mathrm{O}_{4}$. To understand spin-charge-lattice coupling in our nanocrystalline $\mathrm{Fe}_{3} \mathrm{O}_{4}$ films, we plotted normalized $M(\mathrm{~T}) / \mathrm{M}(300 \mathrm{~K})$ vs $\mathrm{T}$ curves measured at different magnetic fields in Fig. 3 for one of the representative samples. We can see that the magnitude of the drop in magnetization below $120 \mathrm{~K}$ is strongly dependent on the applied magnetic field. This feature is an artifact arising out of insufficient magnetic field resulting in non-saturation [shown in Fig. S2(a) in the supplementary material]. This increased non-saturation effect is caused by increased anisotropy in the monoclinic phase of $\mathrm{Fe}_{3} \mathrm{O}_{4}$ below $120 \mathrm{~K}^{23}$ However, no such drop in magnetization is observed in $\mathrm{M}(\mathrm{T}) / \mathrm{M}(300 \mathrm{~K})$ vs $\mathrm{T}$ curve when measured at a 


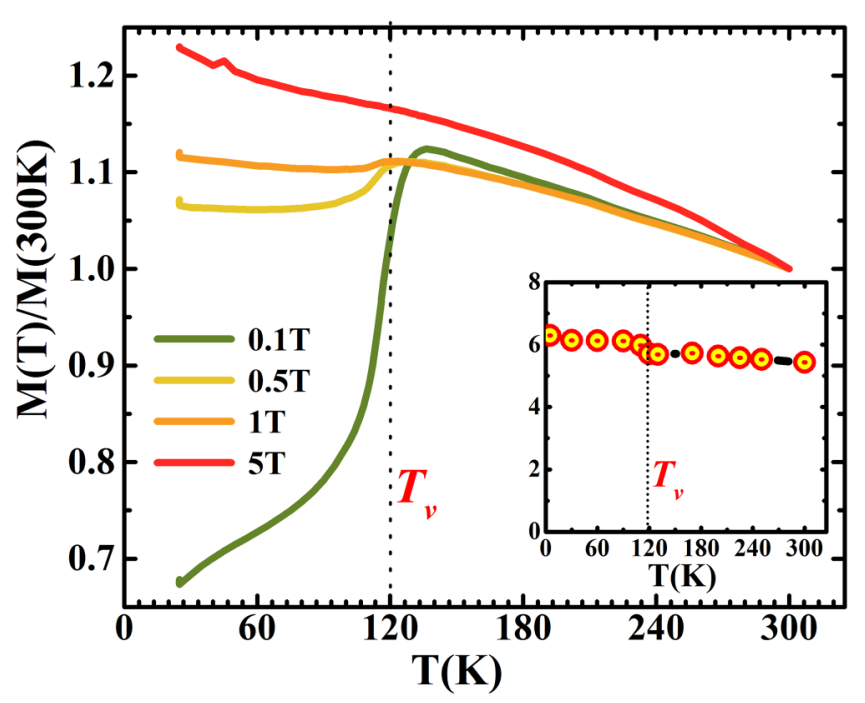

FIG. 3. Normalized $M-T$ curves at various measuring fields for one of the representative samples (wet $\mathrm{H}_{2}$ annealed films with $T_{\mathrm{g}}=\mathrm{RT}$ ). The inset shows magnetization at infinite field $4 \pi M(\infty)$ vs $T$ curve.

fixed magnetic field of $5 \mathrm{~T}$. This raises a question whether this drop in magnetization is due to a change of the magnetic moment of $\mathrm{Fe}_{3} \mathrm{O}_{4}$ or it is just a manifestation of the increased anisotropy. This controversy can be resolved by plotting saturation magnetization (i.e., magnetization at infinite field) $4 \pi \mathrm{M}$ $(\infty)$ vs T curve (inset of Fig. 3), estimated from the Chikazumi non-saturation formula, $4 \pi \mathrm{M}(\mathrm{H})=4 \pi \mathrm{M}(\infty)\left(1-\mathrm{H} / \mathrm{H}^{*}\right)^{1 / 2}$. $^{23}$ This suggests that $4 \pi \mathrm{M}(\infty)$ increases only below $120 \mathrm{~K}$ similar to $\mathrm{M}(\mathrm{T}) / \mathrm{M}(300 \mathrm{~K})$ vs $\mathrm{T}$ curve measured at a sufficiently high field of $5 \mathrm{~T}$ (Fig. 3). Thus, this drop in magnetization occurs only because of the insufficient magnetic field applied which cannot saturate the monoclinic phase of $\mathrm{Fe}_{3} \mathrm{O}_{4}$; otherwise at high fields, sample results typically obey Bloch- $\mathrm{T}^{3 / 2}$ law of ferrites, ${ }^{17}$ without inducing any change at Verwey transition. This also implies that irrespective of the crystal structure transition, this phenomenon can happen even if there is a change in anisotropy. ${ }^{28}$ In the case of $\mathrm{Fe}_{3} \mathrm{O}_{4}$, it is a coincidence that such changes in anisotropy also occur around $120 \mathrm{~K}$. Based on the above discussion, it can be argued that the Verwey transition may not be driven primarily by magnetic interactions and hence the metal-insulator transition has hardly any effect on magnetic properties. This argument is further supported if we consider the Verwey transition as a Mott-type metal-insulator transition, ${ }^{29}$ then, in principle, it does not require a change in either crystal structure or magnetic symmetry, although in practice the coupling between charge, spin, and lattice means that other transitions tend to occur simultaneously. ${ }^{30}$ Moreover, Wang et al. ${ }^{31}$ also support our decoupling argument by not showing the Verwey transition in the electric transport properties and temperature dependent structural evolution even in polycrystalline bulk
$\mathrm{Fe}_{3} \mathrm{O}_{4}$ samples. While their magnetization data still manifested a discontinuous decrease at the $T_{V}$, they attributed these unusual results to the quenching related stresses and defects in the material.

After decoupling of magnetic phenomena, the controversy, often, is to find which comes first: does the structural transition drive the electronic one or is it the other way round. ${ }^{7}$ As the grain boundary volume is not only a factor in electric transport of nano-crystalline $\mathrm{Fe}_{3} \mathrm{O}_{4}$ thin films, the different post-annealing treatments are involved that could also affect the $\mathrm{Fe}^{+3} / \mathrm{Fe}^{+2}$ stoichiometry, residual thermal stresses, and $\mathrm{B}$-site cation and oxygen vacancies differently. ${ }^{1-3,32}$ To elucidate this aspect, we have taken room temperature Raman spectra (within the spectral range $150-800 \mathrm{~cm}^{-1}$ ) of two representative samples $\left(\mathrm{T}_{\mathrm{g}}=\mathrm{RT}\right)$ for each reduction process, as shown in Fig. 4. These spectra were fitted to a sum of Lorentzians which yields line shape parameters: peak position $(\omega)$ and full width at half maximum $(\gamma)$. We observed three strongest modes $\left(\mathrm{A}_{1 \mathrm{~g}}, \mathrm{~T}^{3}{ }_{2 \mathrm{~g}}\right.$, and $\left.\mathrm{T}^{2}{ }_{2 \mathrm{~g}}\right)$ and one faint $\mathrm{T}^{1}{ }_{2 \mathrm{~g}}$ mode of $\mathrm{Fe}_{3} \mathrm{O}_{4}$ phase. The $\mathrm{A}_{1 \mathrm{~g}}$ mode is responsible for the structural property (a symmetric stretch of oxygen atoms along $\mathrm{Fe}-\mathrm{O}$ bonds of tetrahedral A site) and the $\mathrm{T}^{3}{ }_{2 \mathrm{~g}}$ mode

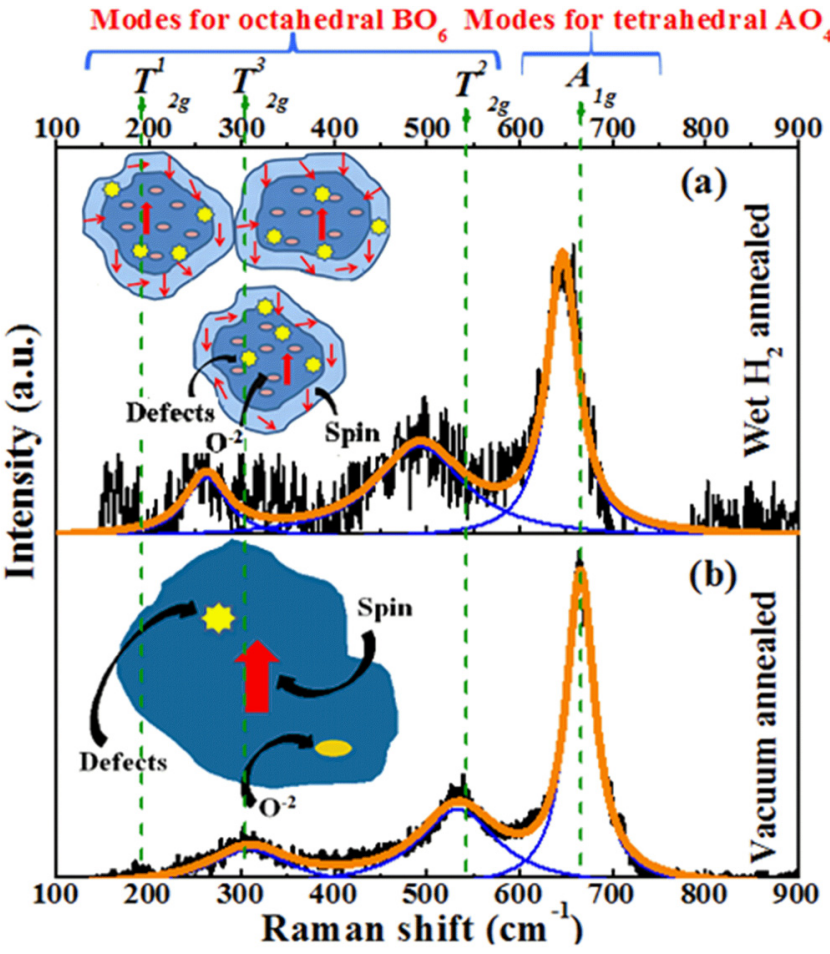

FIG. 4. Raman spectra recorded in the range $100-800 \mathrm{~cm}^{-1}$ at room temperature for (a) wet $\mathrm{H}_{2}$ and (b) vacuum annealed films of $T_{\mathrm{g}}=\mathrm{RT}$. Red arrow shows Raman mode position in bulk cubic $\mathrm{Fe}_{3} \mathrm{O}_{4}$. The solid orange line shows the Lorentzian fitted curves of the peaks due to $A_{1 \mathrm{~g}}$ and $T_{2 \mathrm{~g}}$ modes. Insets show the schematic of the electronic and magnetic disordered grains in both sets of films. 
more for the electronic property (symmetric and asymmetric bending of $\mathrm{Fe}-\mathrm{O}$ bonds of the octahedral $\mathrm{B}$ site) ${ }^{18}$ In wet $\mathrm{H}_{2}$ annealed films, the intensity of the modes is weaker in comparison to vacuum annealed films; their mode position is also significantly shifted toward lower wave numbers, $A_{1 \mathrm{~g}}$ : $646 \mathrm{~cm}^{-1}\left(665 \mathrm{~cm}^{-1}\right)$ and $\mathrm{T}^{3}{ }_{2 \mathrm{~g}}: 262 \mathrm{~cm}^{-1}\left(308 \mathrm{~cm}^{-1}\right)$. It appears that most of these modes are closer to those of nonstoichiometric $\mathrm{Fe}_{3(1-\delta)} \mathrm{O}_{4}{ }^{33}$ When any structural defect/vacancies are created in the $\mathrm{Fe}_{3} \mathrm{O}_{4}$ thin films, the changes in the local electronic network signify a measure of the electron-phonon interaction, which would influence the hopping parameters. In metallic systems, a phonon can decay in an electron-hole pair excitation and extra broadening due to such a decay, as suggested by Allen [Eq. (1)], ${ }^{33}$ can be used to estimate electron-phonon coupling parameter $(\lambda)$ associated with a particular mode $i$ as follows:

$$
\lambda_{i}=\frac{\gamma_{i}}{\omega_{i}^{2}}\left[\frac{g_{i}}{2 \pi \mathrm{N}\left(\mathrm{E}_{\mathrm{F}}\right)}\right],
$$

where $g_{i}$ is the mode degeneracy and $\mathrm{N}\left(\mathrm{E}_{\mathrm{F}}\right)$ is the electronic density of states at the Fermi level. Though precise $\lambda$ cannot be estimated, we attempted to estimate the relative variation in $\lambda$ values. Using theoretically ${ }^{18}$ calculated $N\left(E_{F}\right)\left(3\right.$ states $\mathrm{eV}^{-1}$ f.u. $\left.^{-1}\right)$ value for RT, one estimates that $\lambda$ for the $\mathrm{T}_{2 \mathrm{~g}}^{3}$ mode in wet $\mathrm{H}_{2}$ annealed films $(=2.01)$ is quite large in comparison to vacuum annealed films $(=1.55)$ and bulk $\mathrm{Fe}_{3} \mathrm{O}_{4}(=0.51)$ values. For the $\mathrm{A}_{1 \mathrm{~g}}$ mode, $\lambda$ is fairly constant with $0.13(0.11)$ in both the samples but higher than that of the bulk $\mathrm{Fe}_{3} \mathrm{O}_{4}$ value (0.045), indicating some sort of structural similarity. However, both the samples are different from the electronic structure point of view because in $\mathrm{Fe}_{3} \mathrm{O}_{4}$, near the Fermi level, the electronic states demonstrate $\mathrm{T}^{3}{ }_{2 \mathrm{~g}}$ symmetry and hence couple strongly to $\mathrm{T}^{3}{ }_{2 \mathrm{~g}}$ phonon as compared to $A_{1 g}$ phonons. The enhanced value of $\lambda$ for the $\mathrm{T}^{3}{ }_{2 \mathrm{~g}}$ mode in wet $\mathrm{H}_{2}$ annealed films suggests more localization of electrons at the Fe sites, which could be due to defect/vacancy that affects hopping between $\mathrm{Fe}^{2+}$ and $\mathrm{Fe}^{3+}$ ions at octahedral sites. However, it has little impact on the magnetic interactions among the Fe ions at the tetrahedral $\mathrm{A}$ and octahedral B sites. ${ }^{18}$ The higher value of $\lambda$ for both $\mathrm{T}^{3}{ }_{2 \mathrm{~g}}$ and $\mathrm{A}_{1 \mathrm{~g}}$ modes compared to bulk $\mathrm{Fe}_{3} \mathrm{O}_{4}$ indicates that wet $\mathrm{H}_{2}$ annealed films of smaller grain sizes have more electronic and structural disorder. Thus, they behave more like loosely electron correlated systems which affect $\mathrm{Fe}^{+3} / \mathrm{Fe}^{+2}$ charge ordering and disturb $\mathrm{Fe}^{+3}-\mathrm{Fe}^{+2}-\mathrm{Fe}^{+3}$ trimerons, eventually suppressing the Verwey transition, in electrical transport properties compared to the more ordered phase vacuum-annealed $\mathrm{Fe}_{3} \mathrm{O}_{4}$ films of bigger sizes. Sketches of such electronic and magnetic disorders are depicted in the insets of Fig. 4. It is important to note that though the structural transition is followed by charge ordering in both sets of reduced films, it is the presence of electronic disorder/defects that mask the Verwey transition in wet $\mathrm{H}_{2}$ annealed films.

The transport properties support the Verwey transition and the impact of external and internal factors like annealing conditions and stoichiometry of the ingredients. Since these contain primary information on the mechanism of electronic transport in $\mathrm{Fe}_{3} \mathrm{O}_{4}$, we re-plot the same in terms of $\ln (\rho)$ vs $1 / \mathrm{T}$ curves [as shown in Figs. 5(a) and 5(b)], and the results were fitted to the general expression $\rho=\rho_{0} \exp \left(\mathrm{T}_{0} / \mathrm{T}\right)^{n 18}$ in order to determine whether the conduction regime corresponds to a semiconductor or to a disordered metal. The value of the pre-exponential $\rho_{0}$ indicates whether the conduction occurred by the extended states or by the localized states. $T_{0}$ is a degree of a disorder associated with an activation energy $E_{\mathrm{g}}$ (in the case of semiconductors) and electronic localization length $\xi_{\mathrm{L}}$ (in the case of disordered metals). We found that the best fit was obtained for $n=1$ in wet $\mathrm{H}_{2}$ annealed films in the entire temperature range (300-50 K), indicating semiconducting type behavior with $E_{\mathrm{g}}=93-240 \mathrm{meV}$, which is higher than the reported corresponding bulk $\mathrm{Fe}_{3} \mathrm{O}_{4}$ values $(10-60 \mathrm{meV})^{24}$ (shown in Table I). These values of $E_{\mathrm{g}}$ indicate thermally activated nearest-neighbor-hopping (NNH) mechanism between localized states. The higher values of $\rho_{0}\left(\sim 10^{5}-10^{7} \Omega \mathrm{cm}\right)$ further indicate the presence of a wide range of localization and conduction by hopping in the localized state. Likewise, bulk $\mathrm{Fe}_{3} \mathrm{O}_{4}$, vacuum annealed films exhibit semiconducting behavior with $E_{\mathrm{g}}=20-78 \mathrm{meV}$ above the Verwey transition (300-110 K), wherein thermally activated hopping is dominated at higher temperatures. Below the Verwey transition, these curves deviate from linearity and can be fitted with a value for $n=1 / 4$ corresponding to Mott variable range hopping (VRH) in the interval (110-70 K) due to localization behavior of charge carriers. The in situ growth temperature not only influences $\rho$ and $\mathrm{T}_{\mathrm{V}}$ values but also controls the exact borders of the VRH mechanism in vacuum annealed films, which is also argued in the literature that it arises due to its dependence on purity and the method of preparation. ${ }^{18,24}$ According to the VRH theory, localized carriers form an impurity band, and the low-temperature resistivity is governed by a phonon-assisted hopping of carriers

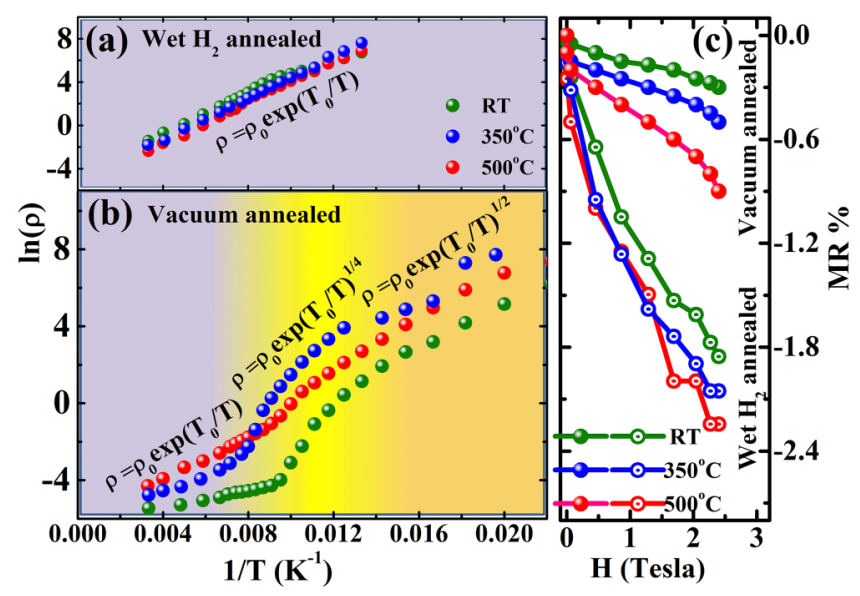

FIG. 5. Plot between (a) $\ln (\rho)$ vs $1 / T$ for wet $\mathrm{H}_{2}$ annealed; (b) vacuum annealed $\mathrm{Fe}_{3} \mathrm{O}_{4}$ films. (c) MR vs $\mathrm{H}$ curves for both sets of films at $300 \mathrm{~K}$. 
between localized states. The parameter $\mathrm{T}_{0}$ (i.e., Mott temperature $T_{M}$ in this case) is related to the density of localized states $\mathrm{N}\left(\mathrm{E}_{\mathrm{F}}\right)$ and localization length $\xi_{\mathrm{L}}$ by the Mott $\mathrm{VRH}^{24}$ relation $\xi_{\mathrm{L}}=\left[18 / k_{\mathrm{B}} \mathrm{N}\left(\mathrm{E}_{\mathrm{F}}\right)\right]^{1 / 3}$. The observed $\mathrm{T}_{\mathrm{M}}$ values $\left(2.4-10 \times 10^{8}\right.$ $\mathrm{K})$ are slightly larger than the earlier reported values for $\mathrm{Fe}_{3} \mathrm{O}_{4}$ films $\left(1.68 \times 10^{8} \mathrm{~K}\right)^{24}$ (shown in Table I). The localization length $\xi_{\mathrm{L}}$, which can be used to describe the spreading of the wave function, is estimated to be smaller than the distance of the nearest Fe ions, which may have occurred because we used $\mathrm{N}\left(\mathrm{E}_{\mathrm{F}}\right)$ value of high-temperature cubic $\mathrm{Fe}_{3} \mathrm{O}_{4}$ phase instead of low-temperature monoclinic phase of $\mathrm{Fe}_{3} \mathrm{O}_{4}$. However, at low temperatures $(70-30 \mathrm{~K})$, resistivity data are neither fit $\mathrm{NNH}$ nor Mott VRH expressions. Instead, they fit well to the Shklovskii and Efros (SE)-VRH model ${ }^{24,34}$ for $n=1 / 2$. We may recall that the Coulomb interactions between charge carriers were ignored in the Mott VRH theory and that $N\left(E_{F}\right)$ was treated as a constant. If the long-range nature of the Coulomb interactions is taken into account, SE found that $\mathrm{N}\left(\mathrm{E}_{\mathrm{F}}\right)$ is no longer a constant, leading to a Coulomb gap $\Delta_{\mathrm{CG}}=k_{\mathrm{B}}\left(\mathrm{T}_{0} \times \mathrm{T}_{\mathrm{C}}\right)^{1 / 2}$, where $\mathrm{T}_{\mathrm{C}}$ corresponds to the crossover temperature from Mott-VRH to SE-VRH ${ }^{21,29}$ and $\mathrm{T}_{0}$ is basically SE temperature (shown in Table I) given by $\mathrm{T}_{\mathrm{SE}}=2.8 e^{2} / 4 \pi \xi_{\mathrm{L}} k \varepsilon_{0}$ (where $k$ is the dielectric constant). Now, $\xi_{\mathrm{L}}$ is approximated to more reasonable $(1.9-2.1 \mathrm{~nm})$ values which are nearly seven times the nearest neighbor hopping distance between $\mathrm{Fe}^{2+}$ and $\mathrm{Fe}^{3+}$ ions at octahedral B-sites. ${ }^{18}$ This indicates the presence of cationic/anionic defects in $\mathrm{Fe}_{3} \mathrm{O}_{4}$, which leads to the localization of charge carriers. When the temperature is high enough for a hopping electron to explore the energy range $\Delta_{\mathrm{CG}}(95-110 \mathrm{meV})$, the influence of the Coulomb gap can be ignored, and one recovers the Mott VRH conduction law. Below $\mathrm{T}_{\mathrm{C}}$, only electronic states inside the Coulomb gap are accessible, and the SE-VRH conduction law is expected to follow. Hence, the resistivity plots of our vacuum annealed films have three linear regions having different slopes, indicating three charge transport mechanisms.

The formation of a defect band and its spin-splitting can also be envisaged via magnetoresistance (MR) measurement, which is essential to study the effect of the density of defect states on the magnetic exchange. Figure 5(c) displays $\mathrm{MR}-\mathrm{H}$ curves for all samples at room temperature. By comparing $\mathrm{MR}-\mathrm{H}$ curves, we found that the MR in wet $\mathrm{H}_{2}$ annealed films $(1.8 \%-2.2 \%)$ is higher than that of vacuum annealed films $(0.3 \%-0.9 \%)$ (cf. Table I), which further supports our argument about the presence of electronic disorder/defects. Interestingly, in situ growth temperature also affects the MR of vacuum annealed films like other electronic and magnetic properties. The higher value of MR in wet $\mathrm{H}_{2}$ annealed films can be explained from the fact that alignment of the disordered spins of the smaller grain boundaries significantly affects the MR because the electrical transport mechanism of the films is due to tunneling. ${ }^{21,32}$ This suggests that the frozen interfacial/ surface moments caused by cationic/anionic defects affect the MR significantly even though they affect the magnetization of the films only slightly. Thus, we observed a slight change in the $\mathrm{Fe}^{3+} / \mathrm{Fe}^{2+}$ ratio, ${ }^{32}$ and defects made the tunneling barrier higher and more stable, enhanced the room temperature MR, and stabilized the $\mathrm{Fe}_{3} \mathrm{O}_{4}$ films chemically. Moreover, the electric transport measurement under various magnetic fields [shown in Fig. S2(b) in the supplementary material] shows no influence on the existence of the Verwey transition, except in the enhancement of MR values in the entire temperature range. This is indicative of no change of spin ordering at the Verwey transition and also the absence of its correlation with charge ordering.

These observations could be useful for the futuristic spintronic applications of nanocrystalline $\mathrm{Fe}_{3} \mathrm{O}_{4}$ thin film devices where annealing is invariably employed.

\section{CONCLUSION}

We have shown how the optimization of the postreduction treatment is crucial in achieving the best electrical transport and magnetic properties in nanocrystalline $\mathrm{Fe}_{3} \mathrm{O}_{4}$ thin films. The following conclusions can be made from the present study:

1. The Verwey transition is a structural transition, which drives charge ordering.

2. This structural transition causes non-saturation effects, and this can lead to a drop in magnetization values around the Verwey transition at low fields. However, application of large magnetic fields can saturate both cubic and monoclinic phases of $\mathrm{Fe}_{3} \mathrm{O}_{4}$, and there should not be any such drop. Saturation magnetization increases upon lowering the temperatures similarly to other ferrites without marking any changes at the Verwey transition. Thus, the Verwey transition has hardly any correlation with magnetic symmetry change, but at low fields owing to increased anisotropy, coercivity, and $M_{R} / M_{S}$, values normally may get changed.

3. Even though structural transition precedes charge ordering in both sets of reduction treated films, it is the electronic disorder/defects that mask the Verwey transition in wet $\mathrm{H}_{2}$ films compared to the vacuum annealed films.

4. No correlation between spin and charge coupling has been found in our nanocrystalline $\mathrm{Fe}_{3} \mathrm{O}_{4}$ thin films.

5. The temperature during in situ growth influences physical properties of vacuum annealed $\mathrm{Fe}_{3} \mathrm{O}_{4}$ films.

\section{SUPPLEMENTARY MATERIAL}

See supplementary material for phase purity check of $\mathrm{Fe}_{3} \mathrm{O}_{4}$ thin films examined by room temperature X-ray spectroscopic data. The non-saturation behavior of $\mathrm{M}-\mathrm{H}$ loops and the absence of magnetic field effect on electric transport properties across the Verwey transition have been demonstrated.

\section{ACKNOWLEDGMENTS}

We thank Dr. S. Prasad and Dr. N. Venkataramani from IIT-Bombay (India) for allowing the use of their experimental facilities. We thank Dr. H. Chou from National Sun Yat-Sen University, Kaohsiung (Taiwan) for technical discussions. We also thank Dr. S. C. Sahoo (Central University of Kerala, India) for magnetic measurements. 


\section{REFERENCES}

'A. Mitra, J. Mohapatra, S. S. Meena, C. V. Tomy, and M. Aslam, J. Phys. Chem. C 118, 19356 (2014).

${ }^{2}$ S. Lim, B. Choi, S. Y. Lee, S. Lim, B. Choi, S. Y. Lee, S. Lee, H.-H. Nahm, Y.-H. Kim, T. Kim, J.-G. Park, J. Lee, J. Hong, S. G. Kwon, and T. Hyeon, Nano Lett. 18, 1745 (2018).

${ }^{3}$ J. Lee, S. G. Kwon, J.-G. Park, and T. Hyeon, Nano Lett. 15, 4337 (2015).

${ }^{4}$ S. D. Jong, R. Kukreja, C. Trabant, N. Pontius, C. F. Chang, T. Kachel, M. Beye, F. Sorgenfrei, C. H. Back, B. Bräuer, W. F. Schlotter, J. J. Turner, O. Krupin, M. Doehler, D. Zhu, M. A. Hossain, A. O. Scherz, D. Fausti, F. Novelli, M. Esposito, W.-S. Lee, Y. D. Chuang, D. H. Lu, R. G. Moore, M. Yi, M. Trigo, P. Kirchmann, L. Pathey, M. S. Golden, M. Buchholz, P. Metcalf, F. Parmigiani, W. Wurth, A. Föhlisch, C. Schüßler-Langeheine, and H. A. Dürr, Nat. Mater. 12, 882 (2012).

${ }^{5}$ Z. Zhang and S. Satpathy, Phys. Rev. B 44, 13319 (1991).

${ }^{6}$ E. J. W. Verwey and P. W. Haayman, Physica 8, 979 (1941).

${ }^{7}$ H. Y. Huang, Z. Y. Chen, R.-P. Wang, F. M. F. de Groot, W. B. Wu, J. Okamoto, A. Chainani, A. Singh, Z.-Y. Li, J.-S. Zhou, H.-T. Jeng, G. Y. Guo, J.-G. Park, L. H. Tjeng, C. T. Chen, and D. J. Huang, Nat. Commun. 8, 1 (2017).

${ }^{8}$ J. P. Wright, J. P. Attfield, and P. G. Radaelli, Phys. Rev. Lett. 87, 266401 (2001).

${ }^{9}$ X. Liu, W. Mi, Q. Zhang, and X. Zhang, Phys. Rev. B 96, 214434 (2017).

${ }^{10}$ M. Hoesch, P. Piekarz, A. Bosak, M. L. Tacon, M. Krisch, A. Kozłowski, A. M. Oles, and K. Parlinski, Phys. Rev. Lett. 110, 207204 (2013).

${ }^{11}$ M. Liu, J. Hoffman, J. Wang, J. Zhang, B. Nelson-Cheeseman, and A. Bhattacharya, Sci. Rep. 3, 1876 (2013).

${ }^{12}$ R. Ramos, T. Kikkawa, K. Uchida, H. Adachi, I. Lucas, M. H. Aguirre, P. Algarabel, L. Morellón, S. Maekawa, E. Saitoh, and M. R. Ibarra, Appl. Phys. Lett. 102, 072413 (2013).

${ }^{13} \mathrm{M}$. Bohra and S. C. Sahoo, J. Alloys Compd. 699, 1118 (2017).

${ }^{14}$ X. H. Liu, W. Liu, Z. D. Zhang, and C. F. Chang, J. Appl. Phys. 123, 083903 (2018).

${ }^{15}$ S. G. Bhat and P. S. Anil Kumar, Mater. Res. Express 3, 125905 (2016).
${ }^{16}$ P. Dey, R. Rawat, S. R. Potdar, R. J. Choudhary, and A. Banerjee, J. Appl. Phys. 115, $17 \mathrm{C} 110$ (2014).

${ }^{17}$ M. Bohra, K. E. Prasad, R. Bollina, S. C. Sahoo, and N. Kumar, J. Mag. Mag. Mater. 418, 137 (2016).

${ }^{18}$ A. Kumar, D. K. Pandya, and S. Chaudhary, J. Appl. Phys. 112, 073909 (2012).

${ }^{19}$ X. Liu, W. Mi, Q. Zhang, and X. Zhang, Appl. Phys. Lett. 113, 012401 (2018).

${ }^{20}$ W. Mi, Z. Guo, Q. Wang, Y. Yang, and H. Bai, Scr. Mater. 68, 972 (2013).

${ }^{21}$ W. B. Mi, J. J. Shen, E. Y. Jiang, and H. L. Bai, Acta Mater. 55, 1919 (2007).

${ }^{22}$ X. Liu, L. Yin, and W. Mi, Sci, Rep. 7, 43403 (2017).

${ }^{23}$ M. Bohra, S. Prasad, N. Venketaramani, N. Kumar, S. C. Sahoo, and R. Krishnan, J. Mag. Mag. Mater. 321, 3738 (2009).

${ }^{24}$ R. Prakash, R. J. Choudhary, L. S. Sharath Chandra, N. Lakshmi, and D. M. Phase, J. Phys. Condens. Matter 19, 486212 (2007).

${ }^{25}$ X. Liu, C. F. Chang, A. D. Rata, A. C. Komarek, and L. H. Tjeng, npj Quant. Mater. 1, 16027 (2016).

${ }^{26}$ B. Ramamurthy Acharya, S. Prasad, N. Venkataramani, S. N. Shringi, and R. Krishnan, J. Appl. Phys. 79, 478 (1996).

${ }^{27}$ T. Kim, S. Lim, J. Hong, S. Gu Kwon, J. Okamoto, Z. Y. Chen, J. Jeong, S. Kang, J. C. Leiner, J. T. Lim, C. S. Kim, D. J. Huang, T. Hyeon, S. Lee, and J.-G. Park, Sci. Rep. 8, 5092 (2018).

${ }^{28}$ H. F. Tian, T. L. Qu, L. B. Luo, J. J. Yang, S. M. Guo, H. Y. Zhang, Y. G. Zhao, and J. Q. Li, Appl. Phys. Lett. 92, 063507 (2008).

${ }^{29}$ J. García and G. Subías, J. Phys. Condens. Matter 16, R145 (2004).

${ }^{30}$ R. G. Moore, J. Zhang, V. B. Nascimento, R. Jin, J. Guo, G. T. Wang, Z. Fang, D. Mandrus, and E. W. Plummer, Science 318, 615 (2007).

${ }^{31}$ L. Wang, J. Li, W. Ding, T. Zhou, W. Zhong, J. Wu, and Y. Du, J. Mag. Mag. Mater. 207, 111 (1999).

${ }^{32}$ W. B. Mi, E. Y. Jiang, and H. L. Bai, J. Phys. D Appl. Phys. 42, 105007 (2009).

${ }^{33}$ R. Gupta, A. K. Sood, P. Metcalf, and J. M. Honig, Phys. Rev. B 65, 104430 (2002).

${ }^{34}$ Y.-L. Huang, S.-P. Chiu, Z.-X. Zhu, Z.-Q. Li, and J.-J. Lin, J. Appl. Phys. 107, 063715 (2010). 